\title{
The Water Scarcity: Imbalanced Supply-and-demand
}

\author{
Yanwan Huang \\ ${ }^{1}$ North China Electric Power University, Baoding071000, China; \\ liusuanlvjia@163.com
}

Keywords: entropy method, NAR prediction model, water scarcity, supply-and-demand

\begin{abstract}
Most countries are suffering the water scarcity. Our goal is to explain the reason of the water scarcity and predict the water resource conditions in the future. We establish a model to quantify the ability of a region to provide the clean water, set an index system to assess the water resource, and establish the prediction model to predict the water situation. By means of analyzing the related indexes of the water situation in numerous regions, we screen out the effective indexes to assess the water resource, and find out the relation between indexes and water supply-and-demand. We determine the weight of each index through the entropy weight method. Due to each index's dimension is different, we standardize each index by means of the modified interval value transformation method to unify the dimension. Further, we make the water supply ability match with the water demand ability to meet the need of its population. We predicted each index's value on the base of the NAR neural net prediction model.
\end{abstract}

\section{Introduction}

The water you drink today has likely been around in one form or another since dinosaurs roamed the Earth, hundreds of millions of years ago. While the amount of freshwater on the planet has remained fairly constant over time-continually recycled through the atmosphere and back into our cups - the population has exploded. This means that every year competition for a clean, copious supply of water for drinking, cooking, bathing, and sustaining life intensifies [1].

While we measure water scarcity, we quantify it and analyze it mathematically as well. Dived the measure of water scarcity into two part, one is the ability of a region to provide clean water, the other is the demand of clean water. When the ability of a region to provide clean water does not match the demands of clean water, the water scarcity is coming.

\section{Measure the ability of a region to provide clean water}

\subsection{Determine the indexes' weight and standardize the indexes}

Considering the implied relation and the surface relation, we set a set $m$ indexes to evaluate the item. Let $x_{i}(i=1,2,3, \ldots, m)$ be the representative of every index. Let $X$ be the set of indexes, then we have

$$
X=\left(x_{1}, x_{2}, \ldots, x_{m}\right)
$$

The weight of indexes can be represented as

$$
W=\left(W_{1}, W_{2}, \ldots, W_{m}\right)
$$

According to the entropy method [6], we can determine the weight. Assuming that there are $n$ items, we set the same $m$ indexes to describe every item. List all the data in a matrix.

$$
\begin{array}{cccc}
x_{11} & x_{12} & \cdots & x_{1 m} \\
x_{21} & x_{22} & \cdots & x_{2 m} \\
\vdots & \vdots & & \vdots \\
x_{n 1} & x_{n 2} & \cdots & x_{n m}
\end{array}
$$


The $j$-th index's entropy is

And the $j$-th index's entropy weight can be represented as

$$
e_{j}=-\frac{1}{\ln m} \times \sum_{i=1}^{m} \frac{x_{i j}}{\sum_{i=1}^{m} x_{i j}} \cdot \ln \frac{x_{i j}}{\sum_{i=1}^{m} x_{i j}}
$$

$$
w_{j}=\frac{\left(1-e_{j}\right)}{\sum_{j=1}^{n}\left(1-e_{j}\right)}
$$

We divide the indexes into positive indexes and negative indexes. As for positive indexes, with the value of indexes increasing, the items get higher. As for positive indexes, with the value of indexes increasing, the items get lower. According to [7], we can improve the positive index formula by

$$
y_{i j}=\frac{x_{i j}-\min _{1 \leq i \leq n}\left(x_{i j}\right) / 1.05}{\max _{1 \leq i \leq n}\left(x_{i j}\right) \times 1.05-\min _{1 \leq i \leq n}\left(x_{i j}\right) / 1.05}
$$

And improve the negative index formula by

$$
y_{i j}=\frac{\max _{1 \leq i \leq n}\left(x_{i j}\right) \times 1.05-x_{i j}}{\max _{1 \leq i \leq n}\left(x_{i j}\right) \times 1.05-\min _{1 \leq i \leq n}\left(x_{i j}\right) / 1.05}
$$

The $i$-th item's ability to provide clean water can be represented as $E_{i}$,

$$
E_{i}=\sum_{j=1}^{m} y_{i j} \cdot w_{j}
$$

The j-th index of the $i$-th item's ability can be represented as

$$
E_{i j}=y_{i j} \times w_{j}
$$

\subsection{Forecast model based on the neural networks model}

Let $h$ be an unbeknown smooth function, the output value for time $t$ can be represented as $Y_{t}$, and the vector of model's parameter can be represented as

$$
\theta\left(\Phi_{1}, \Phi_{2}, \cdots, \Phi_{p}\right)
$$

The nonlinear autoregressive (NAR) model can be considered as:

$$
Y_{t}=h\left(\Phi_{1} Y_{t-1}+\Phi_{2} Y_{t-2}+\cdots+\Phi_{p} Y_{t-p}\right)+e_{t}
$$

Then we have the diagram of the NAR prediction model with one hidden layer.

$$
\hat{Y}_{t}=\hat{h}\left(Y_{t-1}, Y_{t-2}, \cdots, Y_{t-p}\right)=c\left\{\sum_{i=1}^{H}\left[\omega_{i} g\left(\sum_{i=1}^{p} Y_{t-j} \omega_{i(t-j)}+\varphi_{i}\right)\right]+\theta\right\}
$$

In this formula, the input and hidden layers of the network have $p$ and $H$ neurons respectively. The transfer function of the hidden layers and output layers is $g(\cdot)$ and $c(\cdot)$ respectively. The output of the first hidden layer is

$$
Z_{j}=g\left(\sum_{k=1}^{p} Y_{t-k} w_{j(i-k)}+\varphi_{j}\right)
$$

The output of the second hidden layers is

$$
S_{i}=f\left(\sum_{j=1}^{h 1} Z_{j} t_{i j}+\psi_{i}\right)
$$

The output of the output layer is 


\subsection{Numerical Computation}

$$
\hat{Y}_{t}=c\left(\sum_{j-1}^{h 2} S_{i} w_{i}+\theta\right)
$$

According to the original data and objective situation, the author demand a region's indexes as follows. Let "+" be represented as the positive indexes, let "-” be represented as the negative indexes.

Table 1. The indexes

\begin{tabular}{llc}
\hline Dependencies & Index & character \\
\hline \multirow{5}{*}{ Water demand } & irrigated area & + \\
capacity & GDP per capita & - \\
& Agriculture added value & + \\
& Industrial added value & + \\
& Added value of the tertiary industry & + \\
& Population density & + \\
& Natural population growth rate & + \\
& Annual rainfall & + \\
& Surface water resources per capita & + \\
& Groundwater resources per capita & + \\
& Capacity of reservoir & - \\
& Waste water discharge per capita & + \\
& The forest coverage rate & + \\
\hline
\end{tabular}

Measure the ability of water supply (Use the initial of each index instead of the whole spell.)According to the result showed above, the sum of water supply capacity is smaller than the sum of water demand capacity in Hebei, China. It proves that generally Hebei Provence is facing serious water scarcity, the fact is the water supply capacity does not match the water demand capacity.

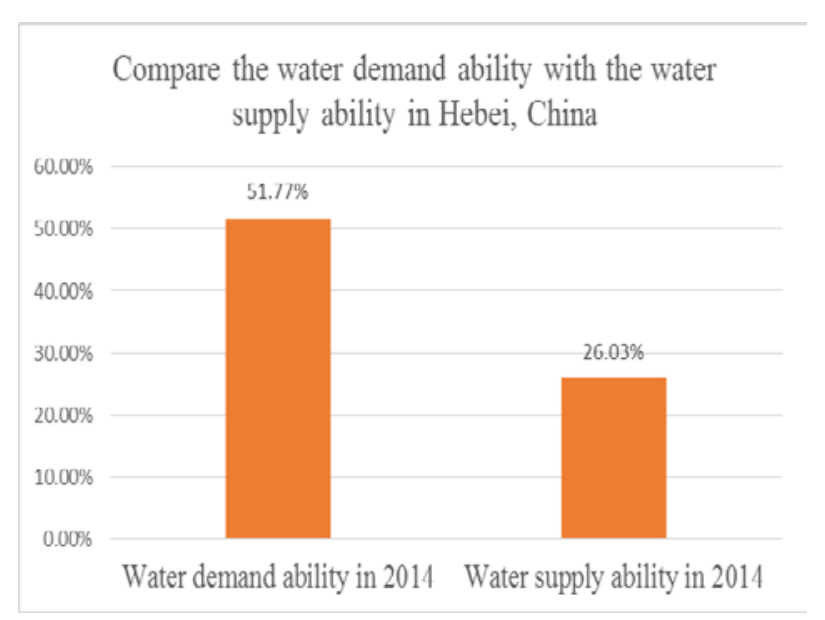

Figure 2. Compare the water demand ability with the water supply ability in Hebei Province.

On the basis of the forecast model based on the neural networks model, plotting the graphs of the indexes from 2014 to 2030 in Hebei province. Owing to the reality, annual rainfall and capacity of reservoir are relatively constants at a certain region. During the process of forecasting, it is reasonable to consider the two indexes as constant values. 


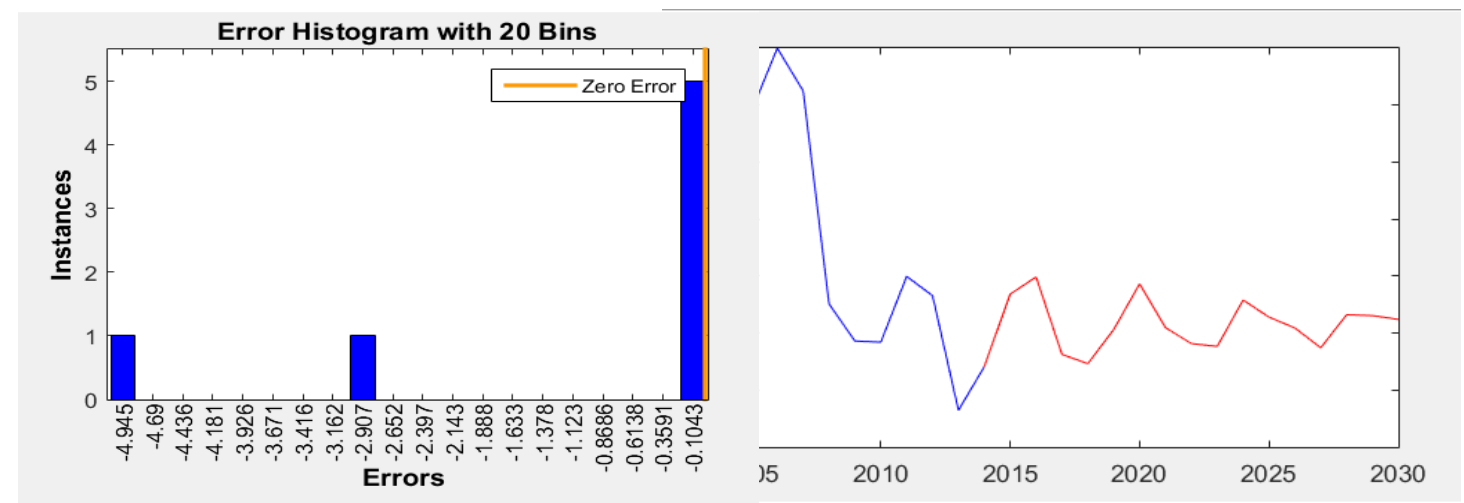

Figure 1. The prediction graphs (Figure (a) is the error histogram of water supplies, Figure (b) is the prediction graph)

\section{Literature References}

What is water scarcity? When an individual does not have access to safe and affordable water to satisfy her or his needs for drinking, washing or their livelihoods we call that person water insecure [2].

During the last few years water has become an increasingly important issue on the earth. There is much talk of a water scarcity, of which the most obvious manifestation is that 1.2 billion people lack access to safe and affordable water for their domestic use [3]. Yet the world's water systems face formidable threats. More than a billion people currently live in water-scarce regions, and as many as 3.5 billion could experience water scarcity by 2025 [4].

Due to geography, climate, industry, agriculture, population, etc. We are heading towards a thirsty planet. The challenge we face now is how to effectively conserve, manage, and distribute the water we have. Many scholars determine the indexes of water, such as The Water Poverty Index (WPI) [5].

\section{Summary}

Reasons for lack of water resources in Hebei Province are as follows. In terms of water demand:

- $\quad \square$ Industrial structure is not reasonable.

- $\quad \square$ The proportion of industry and agriculture in the industrial structure is larger.

- $\quad \square$ The area is the main grain producing areas, so the agricultural irrigation area is very large.

- $\quad \square$ Population density in the area is large.

In terms of water supply:

- $\quad \square$ Because of the climatic reasons of the area, the rainfall is not high.

- $\quad \square$ Per capita surface water and groundwater are far below the world average.

- $\quad \square$ The region's major industries are iron and steel industry and the textile industry, making wastewater discharge is larger, so the water quality is poor.

\section{References}

[1]. Information on: http://environment.nationalgeographic.com/environment/freshwater/freshwater-crisis/

[2]. Frank R. Rijsberman. Water scarcity: Fact or fiction. Agricultural water management: an international journal. Vol. 80 (2006) No. 1-3, p. 5-22.

[3]. Information on: http://www.who.int/water_sanitation_health/hygiene/en/.

[4]. Information on: http://www.wri.org/our-work/topics/water 
[5]. CA Shull. The water poverty index: Development and application at the community scale. Natural Resources Forum. Vol. 27 (2010) No. 3, p. 189-199 